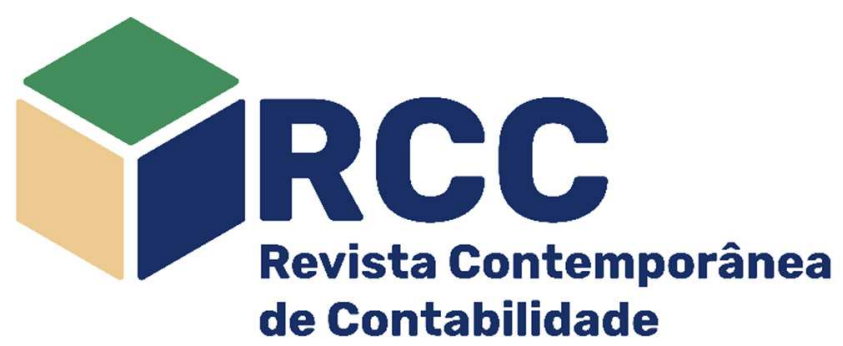

\title{
Gerenciamento de riscos e gestão de controles internos em empresas brasileiras envolvidas em crimes de corrupção e lavagem de dinheiro
}

\author{
Management of risks and internal controls in Brazilian public firms involved in corruption and money \\ laundering scandals
}

Gerenciamiento de riesgos y gestión de controles internos en empresas brasileñas involucradas en crímenes de corrupción e lavado de dinero

\author{
Magali Carvalho Façanha \\ Mestre em Administração e Controladoria (UFC) \\ Gerente de Controladoria Societária na \\ M. Dias Branco S.A. Indústria e Comércio de Alimentos, \\ Eusébio/CE - Brasil \\ magali.facanha@gmail.com \\ https://orcid.org/0000-0002-6000-501X (1) \\ Márcia Martins Mendes De Luca* \\ Doutora em Controladoria e Contabilidade (USP) \\ Professora da Universidade Federal do Ceará (UFC), \\ Fortaleza/CE - Brasil \\ marciammdeluca@gmail.com \\ https://orcid.org/0000-0002-9995-5637
}

Francisco de Assis Pereira de Lima Mestre em Administração e Controladoria (UFC) Professor do Instituto Centro de Ensino Tecnológico (CENTEC), Fortaleza/CE - Brasil assislima3@hotmail.com https://orcid.org/0000-0002-8147-2805 (1)

\author{
Alessandra Carvalho de Vasconcelos \\ Doutora em Engenharia de Produção (UFSC) \\ Professora da Universidade Federal do Ceará (UFC), \\ Fortaleza/CE - Brasil \\ alevasconcelos.ufc@gmail.com \\ https://orcid.org/0000-0002-6480-5620 (1)
}

Endereço do contato principal para correspondência* Av. da Universidade, 2431, Benfica, CEP: 60.020-180 - Fortaleza/CE - Brasil

\section{Resumo}

Diante dos rumorosos escândalos de corrupção e lavagem de dinheiro no país envolvendo empresas de capital aberto, em especial aqueles descobertos pela Operação Lava Jato, percebe-se a fragilidade das companhias no tocante à gestão de controles internos e ao gerenciamento de riscos. Assim, o estudo tem por objetivo identificar as principais características do gerenciamento de riscos e da gestão de controles internos divulgadas nos formulários de referência de companhias de capital aberto listadas na B3, envolvidas em crimes de corrupção e lavagem de dinheiro. Foram analisados os formulários de referência dos exercícios de 2013 a 2016 de seis empresas que vêm sendo investigadas pelo Ministério Público Federal. Observou-se, dentre outras fragilidades, que algumas empresas ainda não adotam uma política de gerenciamento de riscos formal, ou só recentemente passaram a implementá-la, enquanto outras julgam que a gestão de controles internos não tem sido eficaz.

Palavras-chave: Corrupção; Lavagem de dinheiro; Gestão de controles internos; Gerenciamento de riscos

\section{Abstract}

Over the past four years Brazil has been shaken by large corruption and money laundering scandals involving public firms, as revealed by Operation Car Wash, a criminal investigation carried out by the Federal Police, exposing companies' weaknesses in managing internal controls and risk management. In this study we identify the main characteristics of risk management and internal controls disclosed in reference forms of six firms traded on B3, involved in corruption and money laundering crimes and indicted by the Federal Public Ministry. Reference forms published between 2013 and 2016 were analyzed. Among other deficiencies, several of the firms have not yet (or only very recently) adopted a formal risk management policy. In others, internal control management has reportedly been inefficient.

Keywords: Corruption; Money laundering; Internal control management; Risk management 


\section{Resumen}

Frente a los bochornosos escándalos de corrupción y lavado de dinero en el país, comprometiendo empresas de capital abierto, en especial las reveladas por la Operación Lava Jato, se evidencia la fragilidad de las compañías respecto a gestión de controles internos y de riscos. El estudio tiene por objetivo identificar las principales características del gerenciamiento de riesgos y de la gestión de controles internos divulgadas en los formularios de referencia de compañías listadas en la B3, involucradas en crímenes de corrupción y lavado de dinero. Fueron analizados los formularios de referencia de los ejercicios de 2013 a 2016 de seis empresas que vienen siendo investigadas por el Ministerio Público Federal. Entre otras fragilidades, se observó que algunas empresas aún no han adoptado una política de gerenciamiento de riesgos formal, o sólo recientemente empezaron a implementarla, mientras otras juzgan que la gestión de controles internos no ha sido eficaz.

Palabras clave: Corrupción; Lavado de dinero; Gestión de controles internos; Gestión de riesgo

\section{Introdução}

O Brasil tem vivenciado os efeitos de grandes escândalos financeiros, em que o comportamento fraudulento de altos executivos empresariais e de membros do governo provoca um impacto negativo na reputação e na imagem de grandes corporações, comprometendo a sua credibilidade e envolvendo gestores e companhias em processos judiciais relevantes. Dentre esses escândalos, destacam-se aqueles decorrentes do processo de investigação da Operação Lava Jato, conduzida pela Polícia Federal, que teve início em 2009, visando a apurar crimes como corrupção, lavagem de dinheiro e organização criminosa em diversos estados.

Desde 2014, o Ministério Público Federal vem concentrando suas investigações em irregularidades cometidas por fornecedores da maior empresa estatal brasileira, a Petróleo Brasileiro S. A. (Petrobras), na qual descobriu um amplo esquema de pagamentos indevidos, envolvendo diversos participantes, incluindo ex-empregados. O esquema envolvia um grupo de empresas que, entre 2004 e 2012, se organizaram em cartel para obter contratos com a Petrobras e impor gastos adicionais a eles vinculados, utilizando esses valores adicionais em pagamentos indevidos (MPF, 2016).

Levando-se em conta que as organizações estão sujeitas a fraude, importa mencionar que esta se caracteriza pela ação intencional e com dolo praticada por agentes internos ou externos, de forma não autorizada, com vistas a atentar contra os ativos empresariais, suprimindo parte de seus resultados. A fraude visa a assegurar ganhos ilegais, por meio de condutas impróprias, infringindo os princípios da ética e dos valores morais (BRASILIANO, 2015). Segundo Wells (2002), a corrupção é um tipo de fraude em que são envolvidos atos como o suborno e a extorsão, que ferem princípios éticos e valores morais.

Assim, fraudes como a corrupção e a lavagem de dinheiro estão intrinsecamente conectadas, pois muitas vezes ocorrem simultaneamente (MARAGNO; KNUPP; BORBA, 2019; CHAIKIN, 2008). A disseminação mundial da corrupção, tida como um tipo de fraude, foi reconhecida como um dos lados mais sombrios da globalização (KHOJASTEHPOUR, 2015). Wang e You (2012) ressaltam que a corrupção é um dos maiores obstáculos para o crescimento econômico e desenvolvimento social, presente na realidade de todos os países, todavia é percebida com maior intensidade e gravidade em países menos desenvolvidos.

Silva (2012) afirma que procedimentos de monitoramento e acompanhamento de riscos e de controles internos são fundamentais para se detectar a ocorrência e a ameaça de fraudes. Nesse mesmo sentido, Eckert et al. (2014) assinalam que a implementação de controles internos é uma forma de prevenir a ocorrência de fraudes nas organizações. Os controles internos são, portanto, componentes relevantes da gestão de riscos, e essenciais para evitar fraudes, dentre elas, a corrupção.

O risco na empresa é entendido como a existência de situações que impedem o alcance de objetivos corporativos e/ou operacionais, sendo interpretado pelo nível de incerteza associado a um evento (PELEIAS et al., 2017). Já os controles internos podem ser entendidos como o arcabouço de normas sobre procedimentos que visam a tornar rastreáveis os seus processos administrativos, de maneira que as informações necessárias ao bom andamento desse processo sejam fidedignas, proporcionando ao mesmo tempo decisões seguras e a rastreabilidade e a salvaguarda dos ativos da empresa consumidos durante a sua implementação (NASCIMENTO; REGINATO, 2015)

Segundo o Committee of Sponsoring Organizations of the Treadway Commission (COSO, 2007), os controles internos configuram um processo organizacional, conduzido pelo conselho de administração, pela diretoria executiva e pelos demais funcionários, desenvolvido para assegurar, com razoável certeza, que sejam alcançados os objetivos empresariais, nas seguintes categorias: efetividade e eficiência das operações, confiabilidade dos relatórios financeiros e conformidade com as leis e normas aplicáveis.

O gerenciamento de riscos e a gestão de controles internos são temas intercomplementares, haja vista que a utilização de instrumentos de controle interno tem por objetivo conhecer e controlar os riscos, para alcance dos objetivos e metas (CARIOCA; DE LUCA; PONTE, 2010). A avaliação dos controles internos possibilita, portanto, determinar o grau de exposição aos riscos, a eficiência dos controles internos, a qualidade dos planos de ação para corrigir aspectos falhos e/ou vulneráveis e a probabilidade de se alcançar as metas do negócio (CRISANTE NETO; GALHARDO; CRESTO, 2005). 
As informações sobre controle interno nas companhias abertas brasileiras passaram a ser obrigatórias por meio da Instrução Normativa n 480, de 07/12/2009, da Comissão de Valores Mobiliários (CVM, 2009), que instituiu o Formulário de Referência. A CVM editou a Instrução Normativa n 552, de 09/10/2014 (CVM, 2014), introduzindo importantes alterações nas regras de divulgação das companhias abertas, com destaque para a seção 5 do Formulário de Referência, que passou a disciplinar sobre a evidenciação de política de gerenciamento de riscos e gestão de controles internos.

Assim, considerando-se o atual cenário de tantas descobertas de fraude e corrupção, assim como a relevância do gerenciamento de riscos e da gestão de controles internos nas companhias para fortalecer a estrutura de governança, formula-se a seguinte questão de pesquisa: Quais as principais características do gerenciamento de riscos e da gestão de controles internos divulgadas pelas companhias de capital aberto envolvidas em escândalos de corrupção e lavagem de dinheiro?

Para responder a esse questionamento, o presente estudo tem por objetivo geral identificar as principais características do gerenciamento de riscos e da gestão de controles internos divulgadas no Formulário de Referência de companhias de capital aberto listadas na B3 S. A. Brasil, Bolsa, Balcão, envolvidas em crimes de corrupção e lavagem de dinheiro.

Trata-se de estudo de natureza qualitativa, com procedimentos de coleta e de tratamento de dados apoiados nas técnicas de pesquisa documental e análise de conteúdo. Foram investigadas as informações referentes aos exercícios de 2013 a 2016, de empresas listadas na B3.

Diante de um cenário de grande corrupção no país, em especial após os desdobramentos da Operação Lava Jato, as estruturas de controle interno das empresas envolvidas passam, de certa forma, por uma crise de credibilidade (SILVA JUNIOR; VALADARES; MACEDO; 2019). Destarte, destaca-se a relevância do estudo ao levar em conta esse contexto específico em que se percebe a fragilidade da estrutura de governança, em especial do gerenciamento de riscos e dos controles internos nas grandes empresas (FARIAS; DE LUCA; MACHADO, 2009), que gera um ambiente propício para a ocorrência de fraudes.

Portanto, dada a importância dos temas gerenciamento de riscos e gestão de controles internos no contexto corporativo, bem como a repercussão causada pela Operação Lava Jato, nacional e internacionalmente, aliada ao fato de a CVM exigir a prática de divulgação de informações sobre o tema, entende-se que a pesquisa se justifica ainda, por proporcionar contribuições relevantes para a sociedade, para a comunidade acadêmica e para o mercado de capitais, em especial para os investidores, a partir de reflexões sobre a matéria e subsídios para o processo decisório.

\section{Revisão de literatura}

No sentido de aprofundar o entendimento do objeto de pesquisa, apresenta-se, a seguir, uma breve discussão sobre fraude e corrupção, conceitos e caracterização, bem como sobre gerenciamento de riscos e gestão de controles internos.

\subsection{Fraude e corrupção}

Problemas relacionados a ética, uso de recursos públicos em favor próprio ou de terceiros e impunidade de gestores corruptos são frequentemente noticiados nos meios de comunicação. No Brasil o assunto parece estar sempre em pauta na sociedade brasileira (CALDAS; COSTA; PAGLIARUSSI, 2016), pois não é raro observar notícias relacionadas a escândalos de corrupção no país ligados a entidades governamentais (BARROS; FEITOZA, 2019; PORTULHAK; BARILLI, 2016).

lyer e Smociuk (2013) afirmam que os espetaculares colapsos corporativos e as inúmeras grandes fraudes ocorridas nos últimos anos fizeram com que os proprietários, diretores e reguladores de empresas voltassem a atenção e os esforços para compreender e gerenciar os riscos de fraude. Segundo os autores, fraude é o ato de enganar alguém para obter um ganho pessoal e/ou criar uma perda para terceiros. Dessa forma, o risco de fraude é a chance que alguém tem para cometer uma atitude ilícita que venha a causar prejuízo à organização. Esse risco inclui pelo menos três elementos: o método da fraude, a eficiência dos controles e o grau de desonestidade e o nível de habilidade do autor (IYER; SMOCIUK, 2013; MADEIRA; GELISKI, 2019).

A fraude não é fim em si mesmo e, por trás do ato fraudulento, há diversas intenções e motivações. Nesse contexto, o triângulo da fraude se configura como uma das mais conhecidas teorias acerca da ocorrência de fraude (KASSEM; HIGSON, 2012; RUANKAEW, 2016). Segundo o construto, triângulo de fraude ou hipótese de Cressey, como também é conhecida, os três fatores são: i) racionalização: o indivíduo sabe discernir o que é certo e errado, portanto, ele precisa justificar para si mesmo, e para terceiros, que o seu comportamento não é ilegal, vendo-se como uma pessoa honesta; ii) pressão: o fraudador sempre tem um motivo, uma necessidade para realizar a fraude, e isso vai depender da sua situação de vida, ou seja, do contexto em que tem vivido; e iii) oportunidade: é o potencial e a forma como o fraudador utiliza a sua posição e os benefícios que o rodeiam para visualizar uma possível execução ilegal de resolução financeira sem ser descoberto (KASSEM; HIGSON, 2012).

Serra e Ares (2014) constataram que muitas publicações apresentam diferenças entre fraude e corrupção, atribuindo que a corrupção ocorre no setor público, enquanto a fraude ocorre no setor privado. 
Entretanto, segundo Wells (2002), a corrupção é tratada como uma categoria da fraude, que se divide em: corrupção, demonstrações fraudulentas e apropriações indevidas. As subdivisões de cada categoria representam os tipos de fraude que podem ser cometidos. Dentre as subdivisões de corrupção, destacamse: conflito de interesse, suborno, gratificações ilegais e extorsão. Assim, a fraude pode ser cometida em qualquer entidade, seja ela pública ou privada (BATABYAL; CHOWDHURY, 2015; GOMES; MEDEIROS, 2019; WELLS, 2002).

A corrupção pode se manifestar nas organizações sob duas formas: a organização de indivíduos corruptos, cujos membros agem de maneira corrupta em benefício próprio; e a organização corrupta, em que um grupo age coletivamente de maneira corrupta para o benefício da organização (PINTO; LEANA; PIL, 2008). Nos dois arranjos, a organização é a unidade central, ou seja, aquela que agrega os indivíduos em torno de objetivos conduzidos por desvios de conduta, sendo o palco que os agentes corruptos utilizam para cometer seus atos (MIARI; MESQUITA; PARDINI, 2015). Nesse contexto, os atos ilícitos desempenhados por agentes corruptos geram efeitos negativos para a empresa. Negócios de quaisquer naturezas podem sofrer consideráveis perdas devido à corrupção; ou seja, a dimensão dos atos corruptos afeta negativamente os resultados financeiros, e contribui para deteriorar a imagem corporativa (MIARI; MESQUITA; PARDINI, 2015).

Em decorrência da evolução dos meios utilizados para prossecução de atos fraudulentos, os quais impactam negativamente as organizações públicas e privadas, ocasionando perdas patrimoniais, afetando a imagem e criando insegurança e dúvidas acerca da confiabilidade dos processos realizados, ocorreu a necessidade de aperfeiçoamento e adoção de métodos efetivos de combate às fraudes, a fim de mitigar sua ocorrência (PERERA; FREITAS; IMONIANA, 2014).

Dois instrumentos são fundamentais para o combate à fraude no âmbito de uma corporação: o primeiro se relaciona à adoção de um sistema de controles internos, compreendendo mecanismos que dificultem a perpetração de atos fraudulentos nas atividades operacionais; o segundo corresponde a um sistema de contabilidade que atenda aos requisitos de veracidade e clareza das informações que transitam na organização (SILVA, 2012).

A perspectiva mais recorrente sobre a corrupção encontrada nas reportagens de escândalos corporativos é a perspectiva legal, que caracteriza a corrupção como um ato que é proibido pela lei (GOMES; MEDEIROS, 2019). Assim, diplomas como a lei dos Estados Unidos sobre a prática de corrupção no exterior (U. S. Foreing Corrupt Practices Act), de 1977, a lei também norte-americana Sarbanes-Oxley, de 2002, e a lei brasileira anticorrupção (12.846), de 2013 (BRASIL, 2013), aumentaram a responsabilidade da diretoria por uma gestão eficaz dos riscos de fraude (BRASILIANO, 2015) e de corrupção (GOMES; MEDEIROS, 2019).

Entretanto, a fraude continua sendo um problema comum e crescente nas empresas, e decorre do enfraquecimento dos valores éticos, morais e sociais (BRASILIANO, 2015). Portanto, pode-se destacar que a fraude ocorre por oportunidade, devido à ausência de princípios éticos e de valores morais. E esta, por sua vez, sustenta-se em aspectos como controles internos deficientes e falhas nas práticas de gerenciamento de riscos.

\subsection{Controles internos e gerenciamento de riscos}

Conforme já destacado, as organizações estão sujeitas a riscos de fraude, e o Brasil vivencia os efeitos da Operação Lava Jato, em que a atitude fraudulenta de altos executivos de empresas provocou uma grande crise de credibilidade. Nesse contexto, ganham relevância a gestão de controles internos e o gerenciamento de riscos.

O American Institute of Certified Public Accountants (AICPA, 2014) trata controle interno como o plano e todos os métodos e medidas coordenados, aplicados em uma empresa, a fim de proteger seus bens, conferir a exatidão e a fidedignidade de seus dados contábeis, promover a eficiência e estimular a obediência às diretrizes administrativas estabelecidas. Adota-se, neste estudo, a definição do AICPA para o construto controle interno.

O controle interno não é um evento isolado ou uma circunstância eventual, reunindo uma série de ações que permeiam as atividades da organização, e são inerentes ao estilo adotado na condução dos negócios e atividades (D'AVILA; OLIVEIRA, 2002).

Diversos organismos de controle têm proposto modelos de gestão de riscos e controle interno como resposta às pressões dos investidores institucionais e dos mercados. Desse modo, vários países e organismos passaram a elaborar mecanismos de controle que pudessem estabelecer padrões para as empresas. Dentre eles, destaca-se o Committee of Sponsoring Organizations of the Treadway Commission (Coso), uma entidade sem fins lucrativos, dedicada à melhoria dos relatórios financeiros, por meio da ética, efetividade dos controles internos e governança corporativa (FARIAS; DE LUCA; MACHADO, 2009).

Com base na concepção de que o controle interno é um processo, o Coso (2007) divide-o em cinco componentes: ambiente de controle, avaliação de risco, atividades de controle, informação e comunicação e monitoramento. Dessa maneira, o Coso (2007) expõe que o controle interno é um mecanismo de estratégia empresarial, sendo um processo levado a cabo pelo conselho de administração, pela diretoria e por outros membros da organização, com o objetivo de proporcionar um grau de confiança razoável na concretização 
de objetivos como a eficácia e eficiência dos recursos, a confiabilidade da informação financeira e o cumprimento das leis e normas estabelecidas.

Os controles são extremamente necessários, haja vista que podem diminuir os riscos enfrentados pela organização na tentativa de alcançar seus objetivos, razão pela qual demanda ações no sentido de mitigá-los. Assim, controle interno e gestão de riscos seguem um caminho conjunto, que ajuda a instituição a atingir seus objetivos (CASTRO; AMARAL; GUERREIRO, 2019; FARIAS; DE LUCA; MACHADO, 2009).

Todo ambiente de negócios envolve riscos, competindo à administração atuar no sentido de identificálos, mensurá-los, avaliá-los e tratá-los adequadamente (DANTAS et al., 2010). O risco está associado com a incerteza, dando margem a resultados imprevisíveis. Entretanto, sendo detectados com antecedência, abrese a possibilidade de sua gestão (WEBER; DIEHL, 2014).

Os riscos mais comuns atualmente são aqueles relacionados à incerteza de continuidade da empresa, à contabilização errônea de ativos, à falta de aprovação por autoridade competente para a efetivação de pagamentos e/ou financiamentos, à escassez de colaboradores com competência para efetuar procedimentos operacionais e à ausência de segregação de funções para um mesmo processo. Em resumo, uma organização que implanta um sistema de controles internos tem como objetivo prevenir e/ou detectar erros e fraudes, sendo o seu gerenciamento imprescindível no processo de gestão (BEUREN; DALLABONA; DANI, 2011; GOMES et al., 2012; VIDAL; SILVA, 2016).

O gerenciamento de riscos corporativos é um processo conduzido pelo conselho de administração, diretoria e demais empregados, sendo aplicado no estabelecimento de estratégias, formuladas para identificar eventos com potencial de afetar a organização, e administrar os riscos, de modo a mantê-los compatíveis com o apetite a risco da organização e possibilitar uma garantia razoável do cumprimento dos seus objetivos (COSO, 2007). A definição do COSO (2007) é adotada, neste estudo, para o construto gerenciamento de riscos.

Gerenciar risco significa gerenciar a possibilidade de perdas e redução de lucros, e, como o risco é um fator adverso, ele deve ser controlado mediante análise dos objetivos da empresa, bem como sua propensão ao risco, sendo uma das premissas para a gestão baseada em risco (ZONATTO; BEUREN, 2012). A ideia de risco está associada a um certo grau de incerteza, ou seja, corre-se risco quando existe um desconhecimento de resultados futuros de algum evento, ou seja, de algum acontecimento ou ocorrência (CROUHY; GALAI; MARK, 2004; MARUYAMA; RODRIGUES, 2016).

A avaliação dos riscos está relacionada à identificação de falhas de informação relevante e/ou significativa nos relatórios financeiros. Um sistema de controles internos eficaz ajuda a detectar e prevenir erros que são comuns no ambiente organizacional. Conforme seja o nível de eficiência do controle, pode-se avaliar o risco a que a entidade está atrelada com relação à transparência de suas informações (VIDAL; SILVA, 2016).

Yallapragada, Roe e Toma (2012) revelam que as fraudes corporativas decorrem, sobretudo, de falhas nos controles internos organizacionais, pautadas por técnicas e procedimentos complexos que têm a intenção de iludir o mercado (CASTRO; AMARAL; GUERREIRO; 2019). Além disso, destaca-se que, nesse contexto de fraudes corporativas, as empresas e as entidades em geral estão expostas a vários riscos que potencialmente podem levar a indesejáveis consequências financeiras (MACOHON; PETRY; FERNANDES, 2017).

Silva, Marques e Teixeira (2011) pesquisaram o grau de conhecimento e o nível de adesão de empregados de alguns bancos aos procedimentos de controle interno para prevenção à lavagem de dinheiro. Os resultados apontaram que eles detêm conhecimento dos normativos e atuam focados na prevenção à lavagem de dinheiro, sendo que os do único banco estatal de varejo da amostra demonstraram maior aderência aos normativos do que os de bancos privados. Os autores verificaram ainda que o tempo na empresa e o cargo ocupado influenciam o conhecimento dos mecanismos de prevenção à lavagem de dinheiro.

Perera, Freitas e Imoniana (2014) investigaram a eficiência do Sistema de Controles Internos (SCl) no combate às fraudes corporativas, através de uma survey, constatando, por exemplo, que as atividades vinculadas ao SCl têm sido eficazes no combate às fraudes corporativas. Comparando-se as subdivisões da fraude, verifica-se que corrupção e apropriação indébita de ativos têm sido combatidas com mais eficiência pelo canal de denúncias, controles internos e compliance; enquanto isso, as fraudes em demonstrativos financeiros, geralmente vinculadas ao alto escalão corporativo, são percebidas com mais precisão pela auditoria externa.

Silva et al. (2015) analisaram os procedimentos adotados pela gestão de controles internos de uma mineradora. O estudo de caso apontou para a gestão dos controles internos como ferramenta capaz de evitar fraudes, reduzindo custos e proporcionando mais confiabilidade às informações. Verificou-se, ainda, que um intenso controle interno tem a capacidade de minimizar os riscos inerentes às práticas contábeis mal intencionadas, através de uma rigorosa fiscalização e de outros procedimentos.

Monteiro (2015) analisou os objetivos e a importância dos controles internos no setor público brasileiro, assim como as barreiras para sua implementação. $O$ autor concluiu que os controles internos vão além da necessidade de gestão, sendo uma obrigação legal; sua grande importância deve-se ao fato de ser um elemento de mudança na realidade do setor, que carece de melhorias; e que dentre os diversos obstáculos 
a sua implementação destacam-se a falta de uma cultura de gestão do risco, a insuficiência de recursos humanos e de sua capacitação técnica.

Vidal e Silva (2016) procuraram identificar e analisar a percepção dos profissionais de auditoria externa acerca da adequação do sistema de controles internos nas empresas de capital aberto no Brasil. Os resultados do estudo sugerem que, na percepção dos auditores independentes, as empresas da amostra têm plena consciência da importância e dos potenciais benefícios de um adequado sistema de controles internos, apesar das diferentes ênfases observadas e da identificação de aspectos que podem ser aprimorados.

Peleias et al. (2017) buscaram identificar a existência e o uso de controles internos na gestão do risco em vinte empresas de uma rede de autopeças. Os dados foram coletados através de questionários, e o resultado indicou a influência dos riscos no cumprimento dos objetivos corporativos. Os pesquisados reconheceram a presença de uma cultura voltada para a gestão de risco, mas não a percebem como fator de geração de valor agregado ao capital. Constataram que os controles internos são insuficientes para evitar fraudes, exigindo um ambiente ético para sua implementação. A auditoria interna é percebida como um suporte eficaz na identificação do risco, enquanto os relatórios contábeis, sendo a principal fonte de dados, aliam-se a indicadores não financeiros para o monitoramento do risco. Também foi percebido que a gestão de riscos, apesar de burocrática, oferece segurança na gestão das incertezas.

\subsection{Divulgação de informações sobre gerenciamento de riscos e gestão de controle internos}

Em dezembro de 2009, a CVM editou a Instrução Normativa no 480 (CVM, 2009), em substituição à de no 202/1993, dispondo sobre o registro de emissores de valores mobiliários admitidos à negociação em mercados regulamentados. Em seu Anexo 24, a instrução CVM 480 descreve o conteúdo do Formulário de Referência, criado para ser o novo modelo de divulgação de informações das companhias abertas no país, em substituição ao antigo Formulário de Informações Anuais (ARAGÃO; CAVALCANTE, 2014).

O Formulário de Referência é o principal informe de comunicação e de prestação de contas da companhia a todos os stakeholders, já reúne informações relevantes para a compreensão e avaliação da companhia e dos valores mobiliários por ela emitidos, tais como atividades desenvolvidas, estrutura de controle, fatores de risco, dados econômico-financeiros, comentários dos administradores sobre o desempenho, políticas e práticas de governança corporativa e descrição da composição e da remuneração de sua administração (CODIM, 2011).

O Formulário de Referência deve ser visto pela alta administração como um documento estratégico e dinâmico, que deve ser cuidadosamente elaborado e permanentemente monitorado e atualizado sempre que ocorrerem mudanças que afetem seu conteúdo, notadamente nos casos previstos na regulamentação específica (CODIM, 2011).

No tocante às informações sobre controles internos, previstas na seção 10.6 do Formulário de Referência, os diretores devem comentar sobre os controles internos adotados para assegurar a elaboração de demonstrações financeiras confiáveis, indicando o grau de eficiência de tais controles, eventuais imperfeições e providências adotadas para corrigi-las, e deficiências e recomendações presentes no relatório do auditor independente.

Em 2014, a CVM editou a instrução no 552 (CVM, 2014), que, dentre outras mudanças, modificou o Anexo 24 da instrução CVM 480, introduzindo novos requisitos de divulgação de política de gerenciamento de riscos e gestão de controles internos, que passaram a viger em janeiro de 2016. Importante salientar que os itens 5.3.a e 5.3.d foram inseridos e ajustados para contemplar requisitos antes previstos nos itens 10.6.a e 10.6.b, respectivamente. O Quadro 1 mostra os itens 5.1 e 5.3 do Formulário de Referência (Anexo 24) exigidos pela instrução CVM 480, alterada pela de nำ552.

\section{Quadro 1 - Seções 5.1 e 5.3 do Formulário de Referência}

5 Política de gerenciamento de riscos e controles internos

$5.1 \mathrm{Em}$ relação aos riscos indicados no item 4.1, informar:

a. se o emissor possui uma política formalizada de gerenciamento de riscos, destacando, em caso afirmativo, o órgão que a aprovou e a data de sua aprovação, e, em caso negativo, as razões pelas quais o emissor não adotou uma política

b. os objetivos e estratégias da política de gerenciamento de riscos, quando houver, incluindo: i) os riscos para os quais se busca proteção; ii) os instrumentos utilizados para proteção; iii) a estrutura organizacional de gerenciamento de riscos

C. a adequação da estrutura operacional e de controles internos para verificação da efetividade da política adotada

5.3 Em relação aos controles adotados pelo emissor para assegurar a elaboração de demonstrações financeiras confiáveis, indicar:

a. as principais práticas de controles internos e o grau de eficiência de tais controles, indicando eventuais imperfeições e as providências adotadas para corrigi-las

b. as estruturas organizacionais envolvidas

C. se e como a eficiência dos controles internos é supervisionada pela administração do emissor, indicando o cargo das pessoas responsáveis pelo referido acompanhamento

d. deficiências e recomendações sobre os controles internos presentes no relatório circunstanciado, preparado e encaminhado ao emissor pelo auditor independente, nos termos da regulamentação emitida pela CVM que trata do registro e do exercício da atividade de auditoria independente

e. comentários dos diretores sobre as deficiências apontadas no relatório circunstanciado preparado pelo auditor independente e sobre as medidas corretivas adotadas

Fonte: CVM (2009) 
O Quadro 2 mostra os itens exigidos até 31/12/2015 pela instrução CVM 480, e incorporados no Anexo 24 do Formulário de Referência após sua alteração pela instrução CVM 552, que passou a viger em janeiro de 2016.

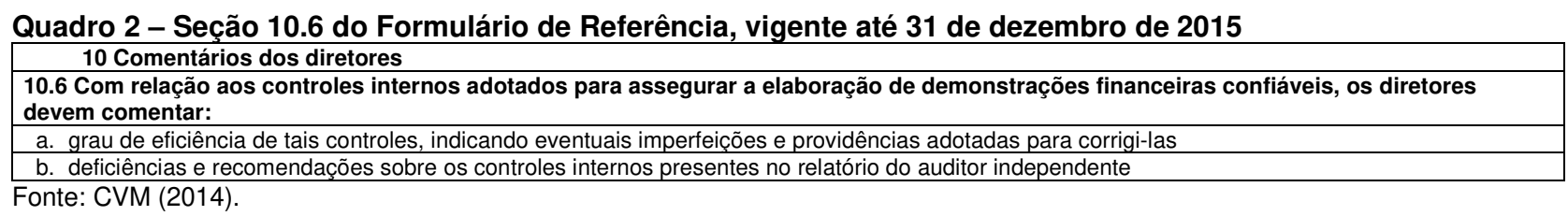

Estudos empíricos anteriores avaliaram a qualidade das informações do Formulário de Referência. Aragão e Cavalcante (2014) investigaram o comportamento das empresas em relação ao preenchimento do Formulário de Referência, no tocante à qualidade das informações, à transparência e às práticas na condução dos negócios, verificando sua adequação às exigências da instrução CVM 480. Em tese, os resultados mostram uma baixa qualidade das informações. Foram registradas tentativas de omissão de informações acerca dos processos e práticas adotados na condução dos negócios, configurando uma não conformidade com as regras da instrução CVM 480 e uma incoerência entre o que é solicitado no Formulário de Referência e as respostas das empresas.

Lopes, Gonçalves e Callado (2016) investigaram o comportamento de empresas brasileiras listadas na New York Stock Exchange (Nyse), no tocante ao preenchimento das informações sobre as fraquezas do controle interno emitidas pelos gestores e empresas de auditoria no Relatório 20-F (formulário para empresas estrangeiras listadas na Nyse, exigido pela Securities Exchange Commission - SEC) e no Formulário de Referência, verificando sua adequação às exigências da Lei Sarbanes-Oxley e à instrução CVM 480, respectivamente. A análise comparativa dos dois relatórios evidenciou que algumas empresas não divulgam as informações sobre as fraquezas do controle interno integralmente no Formulário de Referência.

Diante do exposto, reforça-se a justificativa do estudo, em especial para os stakeholders incursos no mercado de capitais (MARAGNO; KNUPP; BORBA, 2019; WANG; YOU, 2012), ao analisar as informações sobre gerenciamento de riscos e gestão de controles internos divulgadas no Formulário de Referência por companhias de capital aberto envolvidas em crimes de corrupção e lavagem de dinheiro.

\section{Metodologia}

A pesquisa é de natureza qualitativa, visto que lida com a utilização de técnicas interpretativas, objetivando identificar fenômenos para obter elementos relevantes para descreve-los (RICHARDSON, 2009). Em relação aos procedimentos metodológicos, trata-se de uma pesquisa documental, considerando-se que, para se alcançar o objetivo proposto, foi examinado o Formulário de Referência de cada uma das empresas listadas na bolsa brasileira envolvidas em crimes de corrupção e lavagem de dinheiro, a partir da análise de conteúdo.

Segundo Bauer (2011), a análise de conteúdo é um método de análise de texto desenvolvido dentro das ciências sociais empíricas. Trata-se de uma técnica para produzir inferências de um texto focal para seu contexto social de maneira objetiva, reduzindo a complexidade de uma coleção de textos. A teoria e o problema são responsáveis pela seleção e categorização dos materiais de texto, tanto implícita, como explicitamente.

A amostra do estudo compreende as empresas listadas na B3 S. A. Brasil, Bolsa e Balcão investigadas por crimes de corrupção e lavagem de dinheiro, a partir de 2014 (ano de início da operação Lava Jato), com os desdobramentos das investigações da Operação Lava Jato e também da Operação Acrônimo. A seleção das empresas baseou-se em notícias amplamente veiculadas na mídia (principalmente em 2017, período de elaboração desta pesquisa) e confirmadas no Formulário de Referência de cada uma delas. As empresas que fazem parte do estudo são apresentadas no Quadro 3.

\section{Quadro 3 - Empresas objeto do estudo}

\begin{tabular}{|c|c|c|c|c|}
\hline Empresa & Segmento econômico & $\begin{array}{l}\text { Segmento de } \\
\text { listagem }\end{array}$ & $\begin{array}{c}\text { Ano de citação } \\
\text { na investigação } \\
\text { do MPF }\end{array}$ & Operação \\
\hline Braskem S. A. & Petroquímico & Nível 1 & 2014 & Lava Jato \\
\hline Centrais Elétricas Brasileiras S. A. - Eletrobras & Energia elétrica & Nível 1 & 2014 & Lava Jato \\
\hline JBS S. A. & Carnes e derivados & Novo Mercado & 2017 & Lava Jato \\
\hline JHSF Participações S. A. & Edificações & Novo Mercado & 2016 & Acrônimo \\
\hline Marfrig Global Foods S. A. & Carnes e derivados & Novo Mercado & 2015 & Acrônimo \\
\hline Petróleo Brasileiro S. A. - Petrobras & $\begin{array}{l}\text { Petróleo, gás e } \\
\text { biocombustíveis }\end{array}$ & - & 2014 & Lava Jato \\
\hline
\end{tabular}

Fonte: Elaborado pelos autores.

Cinco das seis empresas estudadas se enquadram nos níveis diferenciados de governança corporativa da B3, sendo três (JBS, JHSF e Marfrig) no segmento de listagem de maior exigência de adoção 
de boas práticas (Novo Mercado), e duas no segmento intermediário no tocante a essa característica (Nível 1).

Com base na revisão de literatura e nas exigências da CVM, objeto das seções 5.1 e 5.3 do Formulário de Referência, foram definidas para o estudo as categorias de análise gerenciamento de riscos e gestão de controles internos, e, a partir delas, as respectivas subcategorias, conforme apresentado no Quadro 4. Destarte, as subcategorias do estudo foram definidas, mais especificamente, a partir das exigências das instruções CVM 480/2009 e 552/2014, resumidas nos Quadros 1 e 2.

\begin{tabular}{|c|c|}
\hline Categoria & Subcategoria \\
\hline \multirow{2}{*}{ Gerenciamento de riscos } & 1. Existência de política de gerenciamento de riscos \\
\hline & $\begin{array}{l}\text { 2. Estrutura operacional e de controles internos para verificar a efetividade da política de } \\
\text { gerenciamento }\end{array}$ \\
\hline \multirow{5}{*}{$\begin{array}{l}\text { Controles internos } \\
\text { (para assegurar a elaboração das } \\
\text { demonstrações financeiras) }\end{array}$} & 3. Existência de práticas de controle interno na elaboração das demonstrações financeiras \\
\hline & 4. Divulgação da existência de ineficiência nos controles internos \\
\hline & 5. Estruturas organizacionais envolvidas nos controles internos \\
\hline & 6. Supervisão da eficiência dos controles internos \\
\hline & $\begin{array}{l}\text { 7. Existência de divulgação de ineficiência apontadas no relatório circunstanciado preparado } \\
\text { pelo auditor independente e sobre as medidas corretivas adotadas }\end{array}$ \\
\hline
\end{tabular}

Fonte: Elaborado pelos autores.

A partir das categorias e subcategorias definidas, foi elaborado um checklist para ser utilizado na coleta, e posterior análise de conteúdo, das informações de gerenciamento de riscos e gestão de controles internos divulgadas pelas empresas no Formulário de Referência, com o objetivo de assegurar a elaboração de demonstrações financeiras confiáveis, no período de 2013 a 2016. O Formulário de Referência de cada empresa foi coletado mediante acesso ao website da CVM, e seu conteúdo foi analisado conforme segue: seção 10.6 - exercícios de 2013 e 2014; seções 5.1 e 5.3 - exercícios 2015 e 2016, levando-se em conta a instrução CVM 552.

No que tange à análise de conteúdo, foram observadas as três fases do método, conforme Bardin (2006): (1) pré-análise; (2) exploração do material, que, nesse caso, levou em conta o Formulário de Referência; e (3) tratamento dos resultados, inferência e interpretação. A análise de conteúdo iniciou-se por meio de leitura e interpretação das informações contidas nos textos selecionados. Além dos conteúdos inerentes às sete subcategorias de análise do estudo (Quadro 4), foram analisados trechos que apresentaram as seguintes palavras-chave: "corrupção", "Lava jato" e "Acrônimo".

Assim, em uma primeira análise, quando aplicável, para cada questionamento do checklist foi identificado se houve divulgação da informação. O procedimento seguinte consistiu em se analisar e interpretar o processo de divulgação das informações de gerenciamento de riscos e de gestão de controles internos de cada empresa ao longo do período analisado, de maneira a se perceber as mudanças de reestruturação que porventura tenham sido implementadas diante do contexto da investigação judicial decorrente das operações Lava Jato e Acrônimo.

\section{Análise dos Resultados}

$\mathrm{Na}$ análise de conteúdo das informações do Formulário de Referência, com o propósito de se evidenciar as características dos controles internos e do gerenciamento de riscos divulgadas pelas empresas no período de 2013 a 2016, foram examinadas cada uma das sete subcategorias definidas no Quadro 4, a saber: i) existência de política de gerenciamento de riscos; ii) estrutura operacional e de controles internos para verificar a efetividade da política de gerenciamento; iii) existência de práticas de controle interno na elaboração das demonstrações financeiras; iv) divulgação da existência de ineficiência nos controles internos; v) estruturas organizacionais envolvidas nos controles internos; supervisão da eficiência dos controles internos; iv) existência de divulgação de ineficiência apontadas no relatório circunstanciado preparado pelo auditor independente e sobre as medidas corretivas adotadas.

Cabe informar que a Braskem não divulgou seu Formulário de Referência referente a 2016, razão pela qual as análises aqui apresentadas com relação a essa empresa compreendem apenas os exercícios sociais de 2013, 2014 e 2015.

\subsection{Existência de política formal de gerenciamento de riscos}

O Quadro 5 apresenta informações sobre a existência de política de gerenciamento de riscos por empresa e por ano, que somente a partir de janeiro de 2016 passaram a ser exigidas pelo Formulário de Referência, na seção 5.1, item "a".

A Braskem não esclarece se adota uma política de gerenciamento de riscos, mas ressalta a existência de uma política de gestão financeira e de riscos, aprovada pelo conselho de administração em agosto de 2010. A política versa sobre a gestão de fluxo de caixa e liquidez, investimento das disponibilidades 
financeiras, captação de recursos, dentre outros, com foco em gestão financeira. Portanto, entende-se que não há uma política de gerenciamento de todos os riscos envolvidos nos negócios da companhia, o que diverge da literatura sobre o construto gerenciamento de risco (COSO, 2007; DANTAS et al., 2010; ZONATTO; BEUREN, 201).

Quadro 5 - Existência de política formal de gerenciamento de riscos

\begin{tabular}{|c|c|c|}
\hline Empresa & 2015 & 2016 \\
\hline Braskem S. A. & Não & $\begin{array}{l}\text { Não apresentou Formulário de } \\
\text { Referência }\end{array}$ \\
\hline Centrais Elétricas Brasileiras S. A. - Eletrobras & Sim & Sim \\
\hline JBS S. A. & Não & Não \\
\hline JHSF Participações S. A. & Não & Sim \\
\hline Marfrig Global Foods S. A. & Não & Não \\
\hline Petróleo Brasileiro S. A. - Petrobras & Sim & Sim \\
\hline
\end{tabular}

Fonte: Elaborado pelos autores.

Na Eletrobras, a política de gestão de riscos foi aprovada em julho de 2014, e revisada em 2015, de forma a também atender às novas demandas, de conformidade com leis e regulamentos relacionados às práticas de conduta antiética e corrupção, bem como ao Coso. Em 2016, o documento foi aprovado pela diretoria executiva da holding e ratificado pelo seu conselho de administração, conforme orienta Dantas et al. (2010).

Já a JBS não possui política de gerenciamento de riscos, nem esclarece a razão. Apenas destacou, em seu Formulário de Referência de 2016, a existência de instruções e manuais de procedimentos internos com mapeamento de alguns riscos, manual de conduta ética, dentre outros aspectos. Ressalta, ainda, a criação de um comitê de governança, aprovado pelo conselho de administração em maio de 2017. Destaquese que, no Formulário de Referência de 2015, a empresa mencionou que, em novembro desse mesmo ano, foi aprovada uma política de relacionamento com entidades governamentais e órgãos públicos, com o objetivo de gerenciar os riscos decorrentes de tratativas com esses agentes.

A JHSF, uma das três listadas no Novo Mercado, aprovou, em março de 2016, sua política de gestão de riscos. A empresa informa que pretende criar um comitê de riscos até dezembro de 2017 e implantar uma área de auditoria interna até dezembro de 2018.

A Marfrig iniciou uma revisão de suas políticas de gerenciamento de riscos em 2015, e, de acordo com o Formulário de Referência de 2016, ainda se encontrava pendente de aprovação pelo conselho de administração.

Embora somente em 2016 a CVM tenha passado a exigir a implementação de uma política formal de gerenciamento de riscos, em junho de 2015 a Petrobras já tinha aprovado sua política de gestão de riscos, divulgando-a em seu Formulário de Referência, que registra a adesão da estatal a metodologias como CosoERM e ISO 31000, além de orientações do Instituto Brasileiro de Governança Corporativa (IBGC).

\subsection{Estrutura operacional e de controles internos para verificar a efetividade da política de gerenciamento}

A Braskem não esclarece a estrutura de controle interno para gerenciamento de riscos. Ressalta, apenas, que adotou uma política de gestão financeira e de riscos, aprovada pelo conselho de administração, envolvendo o acompanhamento por parte do diretor presidente, do diretor de relações com investidores e do responsável pela área de finanças.

A estrutura da Eletrobras, tanto em 2015 quanto em 2016, é formada pelas gerências de riscos e controles internos e pelos comitês de riscos presentes em cada uma de suas empresas. A orientação geral é dada pela comissão de riscos da holding, e os resultados obtidos no processo são submetidos à apreciação da sua diretoria executiva, bem como do seu conselho de administração, através do comitê de auditoria e riscos.

A JBS não implementa política de gerenciamento formal para todos os riscos, conforme já relatado, contrariando a literatura (COSO, 2007; DANTAS et al., 2010; ZONATTO; BEUREN, 2012). A empresa considera adequados os manuais e instruções existentes para o gerenciamento do risco que se busca proteger, mas não informa a estrutura empregada.

$\mathrm{Na}$ JHSF encontra-se em fase de implementação a estrutura operacional e de controles internos, conforme já mencionado. Já a Marfrig, em 2015 e 2016, apresenta uma estrutura formada pelo conselho de administração, diretoria executiva e auditoria interna. Quanto à adequação da estrutura para garantir a efetividade do gerenciamento de riscos, a empresa não declina informações adequadas para se compreender como a estrutura está organizada, nem esclarece se segue algum padrão de metodologia de controles internos e gestão de riscos, como a metodologia Coso, por exemplo.

$\mathrm{Na}$ Petrobras, a estrutura é composta por conselho de administração, comitê de auditoria estatutária, diretoria executiva, auditoria interna, diretoria executiva de estratégia, organização e sistemas de gestão, gerência executiva de riscos empresariais e gestores. Segundo o Formulário de Referência de 2015, a 
gerência executiva de riscos empresariais foi incorporada pela diretoria de governança, risco e conformidade, criada em 2014.

\subsection{Existência de práticas de controle interno na elaboração das demonstrações financeiras}

A Braskem ressalta que a sua administração, incluindo o diretor presidente e o diretor financeiro, é responsável por estabelecer e manter adequados controles internos relacionados às demonstrações contábeis, baseados também na metodologia do Coso. Os controles internos e processos relevantes são mapeados e testados no plano anual de auditoria interna.

A Eletrobras divulga sua prática de controle interno, mas também alega limitações. A JBS assinala a existência de prática de controle interno, com destaque para o uso de software integrado, práticas de segurança da informação, auditoria interna, dentre outros, baseada nas metodologias Coso, Cobit e ISO 27001.

A JHSF não registra a prática de controle interno, embora relate que sua proposta de controle interno tem base na metodologia do Coso. A Marfrig não especifica claramente as práticas de controle interno, mencionando apenas o papel da auditoria interna e da auditoria externa na validação dos controles, e conclui que os diretores acreditam na eficiência dos procedimentos e controles internos para garantir a qualidade das demonstrações financeiras. Os achados de Perera, Freitas e Imoniana (2014) e Silva et al. (2015) também confirmam que a eficiência dos controles internos é capaz de assegurar a qualidade das demonstrações financeiras.

A Petrobras declara que a sua administração é responsável pelo estabelecimento e manutenção de eficazes controles internos referentes à preparação e divulgação das demonstrações financeiras, que tem como base o Internal Control - Integrated Framework (2013), emitido pelo Coso; mas não dá detalhes. Os controles internos são autoavaliados pelos gestores, revisados quanto à adequação do desenho e testados pela auditoria interna. Assim como a Eletrobras, a empresa declara que há limitações no controle.

\subsection{Divulgação da existência de ineficiência nos controles internos}

Com base no Quadro 6, verifica-se que das seis empresas analisadas, somente a Eletrobras e a Petrobras divulgam informações sobre a ineficiência dos controles internos.

\begin{tabular}{|c|c|c|c|c|}
\hline Empresa & 2013 & 2014 & 2015 & 2016 \\
\hline Braskem S. A. & Não & Não & Não & $\begin{array}{c}\text { Não apresentou Formulário de } \\
\text { Referência }\end{array}$ \\
\hline Centrais Elétricas Brasileiras S. A. - Eletrobras & Sim & Sim & Sim & Sim \\
\hline JBS S. A. & Não & Não & Não & Não \\
\hline JHSF Participações S. A. & Não & Não & Não & Não \\
\hline
\end{tabular}

Fonte: Elaborado pelos autores.

A Braskem não apresentou deficiências, e seus diretores declararam acreditar na eficiência dos controles internos adotados para assegurar a qualidade das demonstrações financeiras. A Eletrobras julgou ineficazes os seus controles internos para divulgação de informações financeiras em todos os períodos. Dentre as fraquezas apontadas pela empresa, destaca-se o ambiente de controle incompatível com os critérios do Coso.

A JBS não fez qualquer comentário sobre a eficácia dos controles internos. Conforme a literatura, destaca-se que controle interno e gestão de risco são essenciais para o alcance dos objetivos da empresa (CASTRO; AMARAL; GUERREIRO, 2019; FARIAS; DE LUCA; MACHADO, 2009).

A JHSF declara, nos anos 2013 e 2014, que seus controles internos são suficientes para assegurar a elaboração das demonstrações financeiras; mas, em relação a 2015 e 2016, é omissa, fazendo referência somente às recomendações dos auditores.

A Marfrig também não apresentou deficiências, e seus diretores declararam acreditar na eficiência dos controles internos adotados para assegurar a qualidade das demonstrações financeiras. A Petrobras não apresentou deficiências de controles internos no seu Formulário de Referência de 2013, passando a divulgálas somente a partir de 2014, ano em que foi citada na Operação Lava Jato.

\subsection{Estruturas organizacionais envolvidas nos controles internos}

Com base no Formulário de Referência de 2016, as seis empresas analisadas apresentaram as estruturas organizacionais envolvidas nos controles internos, como mostra o Quadro 7. 


\begin{tabular}{|c|c|c|c|c|c|}
\hline Braskem & Eletrobras & JBS & JHSF & Marfrig & Petrobras \\
\hline $\begin{array}{l}\text { Líderes de áreas } \\
\text { de negócios e de } \\
\text { apoio }\end{array}$ & $\begin{array}{l}\text { Conselho de } \\
\text { Administração }\end{array}$ & $\begin{array}{l}\text { Conselho de } \\
\text { Administração }\end{array}$ & \multirow{7}{*}{$\begin{array}{c}\text { Não apresenta } \\
\text { estrutura } \\
\text { organizacional de } \\
\text { controles internos }\end{array}$} & $\begin{array}{c}\text { Diretoria } \\
\text { financeira, com } \\
\text { suporte da } \\
\text { Controladoria } \\
\end{array}$ & $\begin{array}{c}\text { Diretoria Executiva de } \\
\text { Governança e } \\
\text { Conformidade }\end{array}$ \\
\hline Conselho Fiscal & Conselho Fiscal & $\begin{array}{c}\text { Comitê de } \\
\text { Auditoria }\end{array}$ & & $\begin{array}{l}\text { Comitê de } \\
\text { Auditoria }\end{array}$ & $\begin{array}{c}\text { Comitê de Auditoria } \\
\text { Estatutário }\end{array}$ \\
\hline $\begin{array}{l}\text { Comitê de } \\
\text { Conformidade }\end{array}$ & Diretoria Executiva & $\begin{array}{c}\text { Comitê Financeiro } \\
\text { e de Gestão de } \\
\text { Riscos; }\end{array}$ & & $\begin{array}{l}\text { Comitê de } \\
\text { remuneração, } \\
\text { governança } \\
\text { corporativa e } \\
\text { recursos } \\
\text { humanos } \\
\end{array}$ & $\begin{array}{l}\text { Conselho de } \\
\text { Administração }\end{array}$ \\
\hline Auditoria Interna & $\begin{array}{c}\text { Superintendência e } \\
\text { Departamento de } \\
\text { Auditoria }\end{array}$ & Presidente & & $\begin{array}{c}\text { Comitê financeiro } \\
\text { e de gestão de } \\
\text { riscos }\end{array}$ & \\
\hline \multirow[t]{3}{*}{$\begin{array}{c}\text { Conselho de } \\
\text { Administração }\end{array}$} & $\begin{array}{c}\text { Diretoria de } \\
\text { Conformidade }\end{array}$ & Auditoria Interna & & Comitê de gestão & \\
\hline & $\begin{array}{c}\text { Departamentos de } \\
\text { Gestão de Controles } \\
\text { Internos, de } \\
\text { Integridade, de Riscos }\end{array}$ & Compliance & & & \\
\hline & $\begin{array}{c}\text { Superintendências, } \\
\text { Departamentos e } \\
\text { Divisões responsáveis } \\
\text { pelos processos de } \\
\text { negócios }\end{array}$ & & & & \\
\hline
\end{tabular}

Fonte: Elaborado pelos autores.

A JHSF não apresenta estrutura de controles internos, ainda em fase de implantação. Com base na implantação de um novo sistema ERP, a empresa pretende criar o comitê de riscos e a área de auditoria, adequando-se ao que é recomendado pelo COSO (2007) e confirmando-se a relevância dos controles internos, incluindo a auditoria interna, conforme apontado por Peleias et al. (2017).

$\mathrm{Na}$ Braskem, o conselho fiscal tem caráter permanente e exerce funções de comitê de auditoria. A empresa declara possuir um comitê de conformidade, aprovado pelo conselho de administração em maio de 2016. Conforme se pode perceber, as empresas apresentam estruturas diversas, mas todas citam o conselho de administração como participante do processo, exceto a Marfrig.

\subsection{Supervisão da eficiência dos controles internos}

$\mathrm{Na}$ Braskem, todos os resultados de testes de eficácia dos controles internos são supervisionados pelos líderes de processo das áreas de negócios e de apoio, e são reportados ao conselho fiscal. No caso da Eletrobras, cabe à administração estabelecer e manter um ambiente de controles internos adequado, e, inclusive, atender aos requisitos da seção 404 da Lei Sarbanes-Oxley, possibilitando a manutenção da negociação das ADRs nível 2 na Nyse. A empresa destaca que o suporte aos gestores é feito pelas gerências de riscos e controles internos, sob a coordenação de departamento competente.

$\mathrm{Na}$ JBS, a supervisão da eficiência dos controles internos cabe aos membros da diretoria, de forma individualizada, e ao conselho de administração, de forma colegiada, conforme determinado pelo COSO (2007). Brasiliano (2015) e Gomes e Medeiros (2019) também afirmam que a gestão eficaz dos riscos e controles internos é responsabilidade da direção da empresa.

A JHSF informa que não há supervisão, por ainda se encontrar em fase de criação do comitê de riscos e da área de auditoria. Na Marfrig, a supervisão dos controles internos é feita pela área de auditoria interna. Os controles internos da Petrobras referentes à preparação e divulgação das demonstrações contábeis consolidadas são processos desenvolvidos sob a supervisão do presidente, do diretor executivo financeiro e de relacionamento com investidores, do diretor executivo de governança e conformidade e do comitê de auditoria estatutário, vinculado ao conselho de administração.

\subsection{Existência de divulgação de ineficiências apontadas no relatório circunstanciado preparado pelo auditor independente e sobre as medidas corretivas adotadas}

O Quadro 8 indica se as empresas apresentaram informações de ineficiência apontadas nos relatórios dos auditores independentes e de medidas corretivas. A Braskem declarou o desconhecimento de fatores que pudessem suscitar fraquezas nos controles internos com relação à divulgação das demonstrações financeiras. A empresa alegou que as deficiências levantadas pela auditoria independente não são significativas ao ponto de representar probabilidade e magnitude de distorções relevantes das demonstrações contábeis, contrariando a recomendação do $\operatorname{COSO}(2007)$.

A JBS declarou que em 2013 e 2014, na opinião dos diretores, não houve recomendação relevante nos relatórios dos auditores independentes. Já com relação a 2015 e 2016, passou a divulgar o conteúdo dos relatórios dos auditores independentes e os respectivos comentários da administração. 


\begin{tabular}{|c|c|c|c|c|}
\hline Braskem S. A. & Não & Não & Não & $\begin{array}{c}\text { Não apresentou Formuláric } \\
\text { de Referência }\end{array}$ \\
\hline Centrais Elétricas Brasileiras S. A. - Eletrobras & Sim & Sim & Sim & Sim \\
\hline JBS S. A. & Não & Não & Sim & Sim \\
\hline JHSF Participações S. A. & Sim & Sim & Sim & Sim \\
\hline Marfrig Global Foods S. A. & Não & Sim & Sim & Sim \\
\hline
\end{tabular}

Fonte: Elaborado pelos autores.

A Marfrig destaca que os comentários apresentados nos relatórios dos auditores independentes sobre procedimentos e controles internos não mencionaram riscos de distorções relevantes das demonstrações contábeis, individuais e consolidadas, para todos os períodos analisados, destacando algumas recomendações dos relatórios dos auditores em 2015 e 2016, a saber: ausência de sistemas integrados, inexistência de manuais de procedimentos internos e necessidade de revisão de políticas para elaboração de demonstrações financeiras.

A Petrobras divulgou tais ineficiências em todos os anos analisados, mas em 2014 passou a divulgar mais detalhes sobre o conteúdo dos relatórios de recomendação dos auditores, com destaque para as deficiências reveladas após o processo de investigação da Operação Lava Jato. As providências da administração foram no sentido de elaborar planos de ação para fortalecer a governança corporativa, disseminar os valores consignados no código de ética e no guia de conduta, instituir programas de prevenção da corrupção, reestruturar o canal de denúncias e iniciar um processo de investigação interno.

\section{Considerações Finais}

O presente estudo teve por objetivo identificar as principais características do gerenciamento de riscos e da gestão de controles internos divulgadas no Formulário de Referência de companhias de capital aberto envolvidas em crimes de corrupção e lavagem de dinheiro. Para tanto, foi analisado o Formulário de Referência de 2013 a 2016 de empresas envolvidas nas investigações do Ministério Público Federal, listadas na bolsa de valores brasileira, a saber: Braskem S. A., Centrais Elétricas Brasileiras S. A. - Eletrobras, JBS S. A., JHSF Participações S. A., Marfrig Global Foods S. A. e Petróleo Brasileiro S. A. - Petrobras.

Em linhas gerais, foi evidenciado que algumas empresas (i) ainda não implementam uma política de gerenciamento de riscos formal, ou só recentemente passaram a implementá-la, (ii) as estruturas envolvidas para verificar a efetividade da política de gerenciamento são as mais diversas possíveis, mas (iii) basicamente, todas citam a participação de órgãos como o conselho de administração e o comitê de auditoria. Quanto aos modelos de gestão de controles internos, a maioria das empresas cita que adota metodologias baseadas no Coso-ERM ou na ISO 31000; e quanto aos controles específicos para elaboração das demonstrações financeiras, muitas declararam admitir a ineficácia de tais controles.

Entretanto, percebe-se, claramente, que na maioria das empresas estudadas, a divulgação das informações do Formulário de Referência somente passou por algum processo de aperfeiçoamento no que diz respeito à política de gerenciamento de riscos e gestão de controles internos após o envolvimento nas operações de investigação de crimes de lavagem de dinheiro, oportunidade em que as estruturas de governança também foram revisitadas ou estruturadas.

O caso da Petrobras é o que mais chama a atenção na investigação, tendo em vista que a corrupção já permeava as operações desde 2004 e o mercado e a sociedade precisam de uma resposta para tais problemas. Embora a Petrobras não seja listada em nenhum nível diferenciado de governança corporativa na bolsa brasileira, é um tanto surpreendente, considerando-se o porte da empresa e a magnitude de suas operações, a vulnerabilidade em sua estrutura de controle interno, que somente veio à tona com o desenrolar das investigações do Ministério Público Federal. Por outro lado, mesmo as demais empresas listadas em níveis diferenciados de governança corporativa da bolsa de valores brasileira apresentaram idênticas deficiências de controle e fragilidades na estrutura de governança, e, muito possivelmente, reagirão (algumas já estão reagindo) da mesma maneira que a Petrobras, ou seja, implementarão melhorias estruturais por pressão natural do mercado e dos órgãos reguladores.

Dessa forma, algumas questões sobre o tema são intrigantes para o mercado de capitais brasileiro, que podem provocar reflexões para ações mais efetivas. As boas práticas de governança corporativa, incluindo os controles internos e a gestão de riscos, tão difundidas no meio empresarial, estariam sendo negligenciadas? Os níveis diferenciados de governança corporativa da B3, que prezam por rígidas regras de governança corporativa para atrair investidores, e que requerem divulgações mais completas, de forma a reduzir riscos, também estariam "chancelando" as empresas de forma equivocada? As empresas de auditoria também estariam passando por uma crise de credibilidade?

Diante do exposto, observa-se que todo o arcabouço legal e normativo imposto às organizações não parece suficiente para inibir a prática fraudulenta, tornando-se, portanto, necessária a adoção de medidas mais severas. Sabe-se que o grupo de empresas objeto de estudo é pouco representativo para amplas 
generalizações. Contudo, entende-se que as conclusões são suficientes para despertar a atenção dos órgãos reguladores quanto à necessidade de uma revisão dos atuais sistemas de controle das empresas. Por essa razão, este estudo traz contribuições relevantes para a sociedade e para a comunidade acadêmica e empresarial, quando provoca reflexões em torno do tema.

Este estudo amplia pesquisas anteriores no Brasil sobre a gestão de riscos e dos controles internos, utilizando o contexto da operação Lava Jato e da operação Acrônimo, apresentando como as organizações envolvidas em escândalos de corrupção revelam seus mecanismos internos de gestão de riscos e de controles internos para o mercado. Entretanto, entende-se que o estudo apresenta limitações, destacando-se o reduzido número de empresas analisadas e o fato de a exigência de divulgação (no Formulário de Referência) do gerenciamento de riscos e dos controles internos ser relativamente recente (em 2017, período da elaboração desta pesquisa) para as empresas brasileiras (maior detalhamento exigido a partir de 2015), diminuindo, em parte, a compreensão das estruturas antes e depois do envolvimento das empresas em crimes de corrupção e lavagem de dinheiro.

Dessa forma, recomenda-se, para pesquisas futuras, a ampliação do estudo para se considerar um número maior de empresas, além de se analisar um espaço temporal mais ampliado, de forma que se possa compreender as estruturas de controle e de gestão de riscos observando as fragilidades e alterações nos momentos anteriores e posteriores ao envolvimento em investigações policiais.

\section{Referências}

AICPA - American Institute of Certified Public Accountants. Internal Control. 2014. Disponível em: www.aicpa.org/Publications/InternalControl/Pages/InternalControl.aspx. Acesso em: 20 maio 2017.

ARAGÃO, L. A.; CAVALCANTE, D. S. Qualidade das informações do formulário de referência nas empresas brasileiras listadas no Novo Mercado da BM\&FBovespa. RACE - Revista de Administração, Contabilidade e Economia (Online), v. 13, p. 1089-1118, 2014.

BARDIN, L. Análise de conteúdo. Tradução de L. de A. Rego e A. Pinheiro. Lisboa: Edições 70, 2006.

BARROS, E. S.; FEITOZA, G. B. Impacto do Controle da Corrupção sobre a Eficiência do Governo no Ano de 2015: O Caso dos Países da América Latina. Desenvolvimento em Questão, v. 17, n. 49, p. 10-29, 2019. http://dx.doi.org/10.21527/2237-6453.2019.49.10-29

BATABYAL, S.; CHOWDHURY, A. Curbing corruption, financial development and income inequality. Progress in Development Studies, v. 15, v. 1, p. 49-72, 2015. https://doi.org/10.1177/1464993414546980

BAUER, Martin. Análise de conteúdo clássica uma revisão. In: BAUER, Martin; GASKELL, George (Eds.). Pesquisa qualitativa com texto, imagem e som: um manual prático. 9. ed. Petrópolis: Vozes, 2011.

BEUREN, I. M.; DALLABONA, L. F.; DANI, A. C. Disclosure de informações sobre gestão de riscos e controle interno pelas empresas listadas na BM\&FBovespa. Revista de Economia e Administração, v. 10, n. 1, p. 44-65, 2011. https://doi.org/10.11132/rea.2011.444

BRASIL. Lei n. 12.846/2013. Dispõe sobre a responsabilização administrativa e civil de pessoas jurídicas pela prática de atos contra a administração pública, nacional ou estrangeira, e dá outras providências. Diário Oficial, Brasília, DF, $1^{\circ}$ de agosto de 2013.

BRASILIANO, A. C. R. Gestão de risco de fraude. São Paulo: Sicurezza, 2015.

CALDAS, O. V.; COSTA, C. M.; PAGLIARUSSI, M. S. Corrupção e composição dos gastos governamentais: evidências a partir do Programa de Fiscalização por Sorteios Públicos da Controladoria-Geral da União. Revista de Administração Pública (Impresso), v. 50, p. 237-264, 2016. https://doi.org/10.1590/00347612140185

CARIOCA, K. J. F.; DE LUCA, M. M. M.; PONTE, V. M. R. Implementação da lei Sarbanes-Oxley e seus impactos nos controles internos e nas práticas de governança corporativa: um estudo na Companhia Energética do Ceará - Coelce. Revista Universo Contábil, v. 6, n. 4, p. 50-67, out./dez. 2010.

CASTRO, P. R.; AMARAL, J. V.; GUERREIRO, R. Aderência ao Programa de Integridade da Lei Anticorrupção Brasileira e Implantação de Controles Internos. Revista Contabilidade \& Finanças - USP, v. 30, n. 80, p. 186-201, 2019. https://doi.org/10.1590/1808-057x201806780 
CHAIKIN, D. Commercial corruption and money laundering: a preliminary analysis. Journal of Financial Crime, 2008. https://doi.org/10.1108/13590790810882865.

CODIM - Comitê de Orientação para Divulgação de Informações ao Mercado. Pronunciamento de orientação $\mathbf{n}^{\circ}$ 9, de 27 de abril de 2011. Instruções preparativas do formulário de referência. Disponível em http://www.codim.org.br/elaborados.asp. Acesso em: 9 mar. 2017.

COSO - Committee of Sponsoring Organizations of the Treadway Commission. Internal control integrated framework. 2007. Disponível em: <http://www.coso.org>. Acesso em: 15 jul. 2017.

COSO - Committee of Sponsoring Organizations of the Treadway Commission. Gerenciamento de riscos corporativos - estrutura integrada. 2007. Disponível em:

<http://www.coso.org/documents/COSO_ERM_ExecutiveSummary_Portuguese.pdf>. Acesso em: 15 jul. 2017.

CRISANTE NETO, B.; GALHARDO, L. C.; CRESTO, V. Importância da auditoria na avaliação dos controles internos. Resenha BMF, n. 162, p. 64-68, 2005.

CROUHY, M.; GALAI, D.; MARK, R. Gerenciamento de risco: abordagem conceitual e prática. Rio de Janeiro: Qualitymark; São Paulo: Serasa, 2004.

CVM - Comissão de Valores Mobiliários. Instrução CVM n 480, de 7 de dezembro de 2009. Disponível em: <http://cvm.gov.br>. Acesso em: 17 jun. 2017.

CVM - Comissão de Valores Mobiliários. Instrução CVM n 552, de 9 de outubro de 2014. Disponível em: <http://cvm.gov.br>. Acesso em: 17 jun. 2017.

DANTAS, J. A.; RODRIGUES, F. F.; MARCELINO, G. F.; LUSTOSA, P. R. B. Custo-benefício do controle: proposta de um método para avaliação com base no Coso. Revista Contabilidade, Gestão e Governança, v. 13, n. 2, p. 3-19, 2010.

D'AVILA, M. Z.; OLIVEIRA, M. A. M. Conceitos e técnicas de controles internos de organizações. São Paulo: Nobel, 2002.

ECKERT, A.; MECCA, M. S.; BIASIO, R.; PEZZI, G. M. Accounting frauds: characterization and analysis of brazilian scientific publications. Revista Universo Contábil, v. 10, n. 1, p. 84-103, 2014.

https://doi:10.4270/ruc.2014105

FARIAS, R. P.; DE LUCA, M. M. M.; MACHADO, M. V. V. A metodologia Coso como ferramenta de gerenciamento dos controles internos. Contabilidade, Gestão e Governança, v. 3, n. 12, p. 55-71, 2009.

GOMES, P. H. V.; FERREIRA, J. H. M.; DE LUCA, M. M. M.; PONTE, V. M. R. Análise do nível de adesão ao disclosure do risco operacional pelos bancos com ações negociadas na BM\&FBovespa. Revista Razão Contábil \& Finanças, v. 3, n. 1, p. 36-56, jan./jun. 2012.

GOMES, T. G.; MEDEIROS, C. R. O. Construindo e Desconstruindo Escândalos de Corrupção: A Operação Lava-Jato nas Interpretações da Veja e Carta Capital. Organizações \& Sociedade, v. 26, n. 90, p. 457-485, 2019. http://dx.doi.org/10.1590/1984-9260904

IYER, N.; SMOCIUK, M. Risco de fraude: um breve manual para prevenir e detectar fraudes. São Paulo: Sicurezza, 2013.

KASSEM, R.; HIGSON, A. W. The New Fraud Triangle Model. Journal of Emerging Trends in Economic and Management Sciences, v. 3, n. 3, p. 191-195, 2012.

KHOJASTEHPOUR, M. How does corporate social responsibility avoid the incidence of corruption in international expansion? European Business Review, v. 27, n. 3, p. 334-342, 2015.

http://dx.doi.org/10.1108/EBR-01-2015-0002

LOPES, C. C. V. M.; GONÇALVES, R. S.; CALLADO, A. L. C. Controle interno de empresas brasileiras listadas na Nyse: uma comparação entre as informações enviadas à SEC e à CVM. In: CONGRESSO UFPE DE CIÊNCIAS CONTÁBEIS, 10., 2016, Recife. Anais... Recife: UFPE, 2016. 
MACOHON, E. R.; PETRY, J. F.; FERNANDES, F. C. Elaboração do Panorama do Mercado Segurador Brasileiro em Relação à Regulamentação Internacional de Solvência. Revista Contemporânea de Contabilidade, v. 14, n. 31, p. 127-154, 2017. https://doi.org/10.5007/2175-8069.2017v14n31p127

MADEIRA, L. M.; GELISKI, L. O Combate a Crimes de Corrupção pela Justiça Federal da Região Sul do Brasil. Revista de Administração Pública, v. 53, n. 6, p. 987-1010, 2019. http://dx.doi.org/10.1590/0034761220180237

MARAGNO, L. M. D.; KNUPP, P. S.; BORBA, J. A. Corrupção, Lavagem de Dinheiro e Conluio no Brasil: Evidências Empíricas dos Vínculos entre Fraudadores e Cofraudadores no Caso Lava Jato. Revista de Contabilidade e Organizações, v. 13, n. 1, p. 5-18, 2019. http://dx.doi.org/10.11606/issn.19826486.rco.2019.158510

MARUYAMA, U.; RODRIGUES, E. F. Estratégias corporativas para gerenciamento de riscos em controles internos: estudo de caso sobre o processamento eletrônico de cheques. Revista de Contabilidade do Mestrado em Ciências Contábeis da UERJ, v. 21, n. 1, p. 2-11, 2016. https://doi.org/10.12979/13411

MIARI, R. C.; MESQUITA, J. M. C.; PARDINI, D. J. Market efficiency and organizational corruption: study on the impact on shareholder value. BBR. Brazilian Business Review (English Edition. Online), v. 12, p. 123, 2015. https://doi.org/10.15728/bbrconf.\%202015.1

MONTEIRO, R. P. Análise do sistema de controle interno no Brasil: objetivos, importância e barreiras para sua implantação. Revista Contemporânea de Contabilidade, v. 12, n. 25, p. 159-188, 2015. https://doi.org/10.5007/2175-8069.2015v12n25p159

MPF - Ministério Público Federal. Entenda o caso. 2016. Disponível em: http://lavajato.mpf.mp.br/entendao-caso. Acesso em: 14 jun. 2017.

NASCIMENTO, A. M.; REGINATO, L. Controladoria: instrumento de apoio ao processo decisório. 2. ed., rev. e ampl. São Paulo: Atlas, 2015.

PELEIAS, I. R.; EHRENTREICH, H.P.; SILVA, A.F.; FERNANDES, F.C. Pesquisa sobre a percepção dos gestores de uma rede de empresas distribuidoras de um fabricante de autopeças sobre controles internos e gestão de riscos. Revista de Gestão, Finanças e Contabilidade, v. 7, n. 1, p. 6-28, 2017.

http://dx.doi.org/10.18028/rgfc.v7i1.2570

PERERA, L. C. J.; FREITAS, E. C.; IMONIANA, J. O. Avaliação do sistema de combate às fraudes corporativas no Brasil. Revista Contemporânea de Contabilidade, v. 11, n. 23, p. 3-30, 2014.

https://doi.org/10.5007/2175-8069.2014v11n23p3

PINTO, J.; LEANA, C.; PIL, F. K. Corrupt organizations or organizational of corrupt individuals? Two types of organization-level corruption. Academy of Management Review, v. 33, n. 3, p. 685-709, 2008.

PORTULHAK, H.; BARILLI, R. F. Motivações para a expulsão de contabilistas do serviço público federal brasileiro. RACE - Revista de Administração, Contabilidade e Economia (Online), v. 15, n. 2, p. 685704, 2016. https://doi.org/10.18593/race.v15i2.9929

RICHARDSON, R. J. Pesquisa Social: Métodos e Técnicas. 2 ed. São Paulo: Atlas, 2009.

RUANKAEW, T. Beyond the fraud diamond. International Journal of Business Management \& Economic Research, v. 7, n. 1, p. 474-476, 2016.

SERRA, M. F. S.; ARES, E. C. A doação responsável como uma alternativa viável para combater fraudes e corrupções em entidades sem finalidade lucrativa: um estudo do trabalho desenvolvido pela Fundación Lealtad. Revista de Contabilidade do Mestrado em Ciências Contábeis da UERJ, v. 19, n. 2, p. 93-115, 2014. https://doi.org/10.12979/9768

SILVA JUNIOR, A. C.; VALADARES, J. L.; MACEDO, S. V. Desdobramentos da Operação Lava-Jato no Combate à Corrupção no Brasil: Uma Análise a partir da Perspectiva Neo-Institucional. Revista

Pensamento Contemporâneo em Administração, v. 13, n. 4, p. 154-170, 2019.

https://doi.org/10.12712/rpca.v13i3.28415 
SILVA, J. L. R.; MARQUES, L. F. B.; TEIXEIRA, R. Prevenção a lavagem de dinheiro em instituições financeiras: avaliação do grau de aderência aos controles internos. Base, v. 8, n. 4, p. 300-310, 2011. https://doi.org: /10.4013/base.2011.84.03

SILVA, K. H. A.; NASCIMENTO, J. C. H. B.; SOUSA, W. D.; BERNARDES, J. R. O controle interno na prevenção de fraudes: um estudo de caso numa mineradora. Revista Opara, v. 5, p. 43-68, 2015.

SILVA, L. M. Contabilidade forense: princípios e fundamentos. São Paulo: Atlas, 2012.

VIDAL, D. C.; SILVA, A. H. C. A percepção dos auditores externos sobre a adequação dos sistemas de controle interno nas empresas de capital aberto. Pensar Contábil, v. 18, n. 67, p. 57-67, 2016.

WANG, Y.; YOU, J. Corruption and firm growth: Evidence from China. China Economic Review, v. 23, n. 2, p. 415-433, 2012. https://doi.org/ 10.1016/j.chieco.2012.03.003

WEBER, E. L.; DIEHL, C. A. Gestão de riscos operacionais: um estudo bibliográfico sobre ferramentas de auxílio. Revista de Contabilidade do Mestrado em Ciências Contábeis da UERJ, v. 19, n. 3, p. 41-58, 2014. https://doi.org/10.12979/10408

WELLS, J. T. Encyclopedia of fraud. 3. ed. Texas: Association of Certified Fraud Examiners, 2002.

YALLAPRAGADA, R. R.; ROE, C. W.; TOMA, A. G. Accounting Fraud, and White-Collar Crimes in The United States. Journal of Business Case Studies (JBCS), v. 8, n. 2, p. 187-192, 8 Feb. 2012.

https://doi.org/10.19030/jbcs.v8i2.6806

ZONATTO, V. C. S.; BEUREN, I. M. Evidenciação das características básicas recomendadas pelo Coso (2004) para a gestão de riscos em ambientes de controle no relatório da administração de empresas brasileiras com ADRs. Contextus, v. 10, n. 1, p. 77-98, 2012. https://doi.org/10.19094/contextus.v10i1.191

\section{NOTAS}

\section{AGRADECIMENTOS}

Não se aplica.

\section{CONTRIBUIÇÃO DE AUTORIA}

Concepção e elaboração do manuscrito: M. C. Façanha, F. A. P. Lima, M. M. M. De Luca, A. C. Vasconcelos Coleta de dados: M. C. Façanha, F. A. P. Lima

Análise de dados: M. C. Façanha, F. A. P. Lima, M. M. M. De Luca, A. C. Vasconcelos

Discussão dos resultados: M. C. Façanha, F. A. P. Lima, M. M. M. De Luca, A. C. Vasconcelos

Revisão e aprovação: M. C. Façanha, F. A. P. Lima, M. M. M. De Luca, A. C. Vasconcelos

\section{CONJUNTO DE DADOS DE PESQUISA}

Todo o conjunto de dados que dá suporte aos resultados deste estudo foi publicado no próprio artigo.

\section{FINANCIAMENTO}

Não se aplica.

\section{CONSENTIMENTO DE USO DE IMAGEM}

Não se aplica.

\section{APROVAÇÃO DE COMITÊ DE ÉTICA EM PESQUISA \\ Não se aplica.}

\section{CONFLITO DE INTERESSES}

Não se aplica.

\section{LICENÇA DE USO}

Os Direitos Autorais para artigos publicados neste periódico são do autor, com direitos de primeira publicação para a Revista. Em virtude de aparecerem nesta Revista de acesso público, os artigos são de uso gratuito, com atribuições próprias, em aplicações educacionais, de exercício profissional e para gestão pública. A Revista adotou a licença Creative Commons Atribuição 4.0 Internacional - CC BY NC ND. Esta licença permite acessar, baixar (download), copiar, imprimir, compartilhar, reutilizar e distribuir os artigos desde que com a citação da fonte, atribuindo os devidos créditos de autoria. Nesses casos, nenhuma permissão é necessária 
por parte dos autores ou dos editores. Autores têm autorização para assumir contratos adicionais separadamente, para distribuição não-exclusiva da versão do trabalho publicada nesta revista (ex.: publicar em repositório institucional ou um capítulo de livro).

\section{PUBLISHER}

Universidade Federal de Santa Catarina. Curso de Ciências Contábeis e Programa de Pós-graduação em Contabilidade. Publicação no Portal de Periódicos UFSC. As ideias expressadas neste artigo são de responsabilidade de seus autores, não representando, necessariamente, a opinião dos editores ou da universidade.

\section{EDITORES}

Carlos Eduardo Facin Lavarda e Suliani Rover

\section{HISTÓRICO}

Recebido em: 17/03/2018 - Revisado por pares em: 20/04/2020 - Reformulado em: 13/05/2020 Recomendado para publicação em: 05/06/2020 - Publicado em: 30/06/2020 